\section{Mieloma Múltiple: Métodos de Diagnóstico}

Multiple Myeloma: Diagnostic Methods
Marjorie Katiuska Ángulo Segura

Médico general. Hospital General

Esmeraldas Sur Delfina Torres de Concha,

marjorieangulo25@gmail.com,

https://orcid.org/0000-0001-5931-7350;

Guayaquil Ecuador

Edwin Rommel Llanos Oquendo

Médico general. Hospital Básico José

Cevallos Ruiz, romel_90@hotmail.com,

https://orcid.org/0000-0001-8410-7312;

Guayaquil Ecuador

Carlos Joel Cueto Barrera

Médico general. Hospital Luis Vernaza,

carcuet@hotmail.com,

https://orcid.org/0000-0003-3926-521X;

Guayaquil Ecuador

Marco Vinicio Culqui Sánchez

Médico general. Hospital José María

Velasco Ibarra,

marcoculquisanchez@hotmail.com,

https://orcid.org/0000-0002-8957-1752,

Guayaquil Ecuador

http://www.jah-journal.com/index.php/jah

Journal of American health

Julio - Diciembre vol. 3. Num. 2- 2020

Esta obra está bajo una Licencia Creative

Commons

Atribución-NoComercial-CompartirIgual

4.0 Internacional.

RECIBIDO: 8 DE MARZO 2019

ACEPTADO: 19 DE NOVIEMBRE 2019

PUBLICADO: 2 DE JULIO 2020

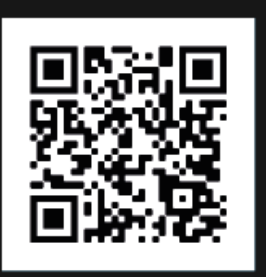

Scan this QR

code with your

smart phone or

mobile device to

read more papers

\section{RESUMEN}

El mieloma múltiple (MM) es una proliferación monoclonal neoplásica de células plasmáticas, con afección más frecuente a la médula ósea, requiere un sinnúmero de métodos diagnósticos para conocer la estatificación, tratamiento y seguimiento. Requiere evidenciar la existencia en sangre $u$ orina de la proteína monoclonal (componente $\mathrm{M}$ ), mediante la cuantificación de inmunoglobulinas séricas, electroforesis de proteínas, inmunofijación, aspirado y biopsia unilateral, citogenética. Otros métodos como la gammagrafía ósea se ven afectadas por una baja sensibilidad. Tc-99m MIBI se ha propuesto en la estatificación y en el seguimiento, la tomografía por emisión de protones (PET FDG) se ha propuesto en MM por su habilidad para detectar la enfermedad metabólica activa de todo el cuerpo. Además, se está realizando un gran esfuerzo científico para redefinir el monitoreo de la respuesta del tratamiento del mieloma múltiple (MM), lo que resulta en el desarrollo y la validación de técnicas de alta sensibilidad para detectar la enfermedad residual mínima (MRD), sin embargo quedan cuestionamientos aún sin responder sobre estos métodos que la evolución clínica del paciente.

PALABRAS CLAVE: Mieloma Múltiple, Diagnostico, revisión, clínica

\section{ABSTRACT \\ Múltiple myeloma (MM) is a neoplastic monoclonal proliferation of plasma cells, with more frequent affection to the bone marrow, and requires a number of diagnostic methods to know the staging, treatment and follow-up. It requires evidence of the existence in the blood or urine of the monoclonal protein}


(component $\mathrm{M}$ ), by means of the quantification of serum immunoglobulins, protein electrophoresis, immunofixation, total protein in 24-hour urine, aspiration, and unilateral cytogenetic biopsy using fluorescence in situ hybridization (FISH). Other methods like bone scan are affected by low sensitivity. Tc-99m MIBI has been proposed in staging and follow-up, proton emission tomography (PET-FDG) has been proposed in MM for its ability to detect active metabolic disease throughout the body. Furthermore, a great scientific effort is being made to redefine the monitoring of the response of the treatment of multiple myeloma (MM), resulting in the development and validation of highly sensitive techniques to detect minimal residual disease (MRD), however questions remain unanswered about these methods other than the clinical evolution of the patient.

KEYWORDS: Multiple Myeloma, Diagnosis, review, clinic

\section{INTRODUCCIÓN}

El mieloma múltiple es una entidad maligna, que causa proliferación anormal de células plasmáticas. Caracterizada por la presencia de plasmocitosis en la médula ósea, producción de proteínas monoclonales, lesiones osteolíticas, insuficiencia renal, anemia, hipercalcemia e inmunodeficiencia (1)

Su incidencia es relativamente baja, aunque cada vez existen más reportes. Su etiología es diversa, comprende procesos infecciosos, tumorales, sistémicos e idiopático. El diagnóstico se da por sospecha clínica, líquido cefalorraquídeo y neuro-imagen. (2).

Entre los agentes etiológicos infecciosos se encuentran: Herpes simple 1 y 2, Varicela zóster, Virus West Nile, HIV (virus de la inmunodeficiencia humana), HTLV-1, Borrelia spp., Mycoplasma pneumoniae, Treponema pallidum, entre otros. (3)

El diagnóstico precoz de esta enfermedad es crucial, por esto una historia asociada a una exploración neurológica minuciosa debe considerarse ya que se trata de una patología tiempodependiente, existiendo constancia de que la intervención precoz mejora el pronóstico de estos pacientes y disminuye en un gran porcentaje las secuelas. (4) (5).

Se manifiesta con síntomas tanto motores como sensitivos, dependiendo de su compromiso espacial. El pronto y oportuno diagnóstico de la MTA (mielitis transversa aguda) va a ser muy importante en el pronóstico del paciente y del tratamiento. (6). Requiere demostrar que existe inflamación de la médula espinal. (7).

Por otro lado, la mielitis puede aparecer como un síntoma inicial en el contexto de enfermedades desmielinizantes, enfermedades inflamatorias sistémicas y enfermedades infecciosas. (4)

La mielitis transversa es una inflamación focal poco frecuente de la médula espinal. Su etiología es múltiple y entre ellas se encuentran las enfermedades autoinmunes, incluyendo principalmente el lupus eritematoso sistémico y el síndrome de Sjögren (8). Síntomas similares 
a bandas de sensación alterada o dolor en forma horizontal, a un nivel específico de dermatoma también están presentes. (9).

La mielitis transversa corta (STM) se considera poco frecuente en los trastornos del espectro óptico de neuromielitis (NMOSD). El mal reconocimiento de STM que ocurre en NMOSD puede conducir a un mayor retraso en el diagnóstico y el tratamiento adecuado. (10)

Los hallazgos clínicos, los exámenes de laboratorio y el uso de la resonancia magnética con gadolinio son pilares fundamentales para realizar el diagnóstico oportuno e iniciar el tratamiento precoz de la enfermedad. Los fármacos estándares son la combinación de ciclofosfamida y glucocorticoides por vía intravenosa. (11).

Se pretende describir los métodos diagnósticos establecidos de acuerdo al nivel de atención y la necesidad del paciente a través de una revisión documental sobre diagnósticos del mieloma multiple.

\section{MATERIALES Y MÉTODOS}

Estudio descriptivo, documental cuyos datos fueron recolectados a través de fuentes secundarios en revistas indexadas, libros, sitios web publicados en los últimos cinco años 2015 al 2020 salvo los de relevancia científica de años previos, utilizando las palabras claves métodos, diagnósticos, mieloma, múltiple, revisión, se escogió entre los idiomas el inglés y español se descartaron otros; seleccionado 28 artículos de los cuales 10 fueron imprescindibles y relevante para alcanzar el objetivo de esta investigación, los cuales se desglosan en serie de casos clínicos donde describe las características clínicas relevantes de los pacientes aplicado a la práctica sobre mieloma múltiple ( $\mathrm{MM})$, así también se elaborara un resumen sobre los método diagnostico a fin demostrar la presentación más frecuente del mieloma múltiple.

\section{RESULTADOS}

Caso 1 Descrito por Cecilia Martínez, 2018, se trata de una mujer de 17 años de edad sin enfermedades previas, quien consultó por dificultad para la marcha y disnea de medianos esfuerzos con irradiación retroesternal, con 48 horas de inicio de síntomas y progresión paulatina. Recibe tratamiento inicial con bolos de metilprednisolona, y luego mantenimiento de $1 \mathrm{mg} / \mathrm{kg} /$ día con mejoría clínica significativa. Se evidencia recuperación de la sensibilidad en ambos miembros, con secuela anestesia en parches, logró control de esfínter anal, sin recuperación completa del esfínter vesical (12)

Caso \# 2: Castro Jordán \& Castillo Solís, 2008 describe un paciente de sexo femenino de 83 años de edad, es internada en el hospital Elizabeth Sentón el 18 de junio del 2007, con cuadro clínico de aproximadamente 6 días de evolución presenta alza térmica, rinorrea y tos seca, dolor abdominal moderado de tipo opresivo en epigastrio e hipocondrio derecho. Se indica una dieta balanceada con $15 \mathrm{gr}$. de calcio, se descontinua soluciones parenterales, es tratado con 
Ciprofloxacina 500 mgVO 2/día, Omeprazol 20 mg VO 2/día, Hemodiálisis 2 hrs, UFT 150mL, transfusión de concentrado eritrocitario 1 unidad $\mathrm{O}_{+}$, durante los cuatro días de internación, sin embargo persisten los accesos de tos y el dolor articular. (13)

Caso \# 3 Maribel Quintero, 2003 menciona una serie de 22 casos, donde destaca la prevalencia de estos casos en Maracaibo Venezuela en un periodo de 4 años, corresponden a ambos sexos, tomadas de muestras de médula ósea (MO), para estudio cromosómico, provenientes de pacientes con al menos uno de sus progenitores venezolano, con diagnóstico de Mieloma Múltiple, clasificados según Durie y Salmón, realizándose el tratamiento con citostáticos. (14)

Caso \# 4 Hermes Moreno Ramírez, 2015, presenta un paciente masculino de 75 años que inicia hace 6 semanas con dolor en la región dorsal, en hemitorax izquierdo de moderada intensidad, con irradiación hacia el tórax anterior, acompañado de disnea de medianos esfuerzos; con datos de insuficiencia renal aguda, deshidratación y síndrome de hiperviscosidad, anemia y EPOC sin tratamiento, exfumador, desde los 17 años, consumió hasta 15 cigarrillos diarios, dejó de fumar hace 18 años; con síndrome de hiperviscosidad inmunofenotipo para mieloma. Se le inició manejo médico con hiperhidratación por insuficiencia renal aguda con la cual ingresó, furosemide $20 \mathrm{mg}$ vía intravenosa cada $12 \mathrm{~h}$, talidomida $100 \mathrm{mg}$ vía oral cada $24 \mathrm{~h}$, alopurinol $150 \mathrm{mg}$ vía oral cada $24 \mathrm{~h}$, bicarbonato $1 \mathrm{~g}$ vía oral cada 8 h, dexametasona $40 \mathrm{mg}$ intravenosa cada $24 \mathrm{~h}$; con respuesta favorable al tratamiento establecido con mejoría clínica y de los resultados de laboratorio por lo cual se decide su egreso del servicio y cita a consulta externa para su manejo. (15).

Caso \# 5 Luis G. Ramón Rodríguez, 2010 en agosto de 2005, describe una mujer gestante de 31 años, blanca, fue ingresada en el Servicio de Ginecobstetricia del Hospital General Docente "Enrique Cabrera" por anemia severa. Los síntomas y signos más importantes fueron fatiga, dolor lumbar intenso, disnea de esfuerzo y palidez cutáneo-mucosa.

La tomografía axial computadorizada y estudio radiológico se inició tratamiento con 6 ciclos de poliquimioterapia con esquema VAD (vincristina, adriamicina y dexametasona). Como tratamiento adyuvante se administró Zometa (ácido zoledrónico) con un suplemento de vitamina $\mathrm{D}$ y calcio. Durante la primera mitad de la terapia se transfundió en 2 oportunidades 
más, por lo que fue necesario a eritropoyetina y fumarato ferroso con una buena respuesta. (16).

Caso \# 6 Irene Castro, 2018, presenta un paciente masculino de 49 años con antecedentes de Hipotiroidismo, Hipertensión arterial, Cardiopatía coronaria isquémica y LES diagnosticado en 1997 a los 31 años dolor en muslo derecho, resulta con diagnóstico de Mieloma Múltiple manifestado en la resonancia magnética nuclear, TAC de cuello, Mielograma. Inició tratamiento con Ciclofosfamida 50 mg día, Talidomida 100 mg día por medio, Dexametasona $40 \mathrm{mg}$ día y Pamidronato $90 \mathrm{mg}$ mensual. Por compromiso de $40 \%$ cuerpo y muro posterior vertebral y riesgo de fractura de cadera se indicó radioterapia en pelvis. Respuesta completa tras 12 meses de tratamiento. Se programó trasplante autólogo de médula ósea (TAMO), no realizado por obtención insuficiente de progenitores hematopoyéticos, falleció el 02 de junio de 20168 años posterior a realizar su diagnotico. (17).

Caso \# 7 Zhou, 2018 en su publicación sobre un caso femenino de 63 años refiere que fue hospitalizada por hematemesis durante dos semanas. Mostró una marcada anemia normocrómica hematemesis durante dos semanas, [hemoglobina, 66 (rango normal: 113-151) g / L; volumen corpuscular medio (MCV), $91.5 \mathrm{fL}$ (rango normal: 84.0-94.0) Fl se realiza esofagogastroduodenoscopia, colonoscopia, TC abdominal, Colonoscopia, donde se realiza diagnóstico definitivo de mieloma múltiple $\lg \mathrm{G} / \lambda$. Se le administró quimioterapia con ciclofosfamida (Hengrui Medicine Co. Ltd, Jiangsu, China) 400 mg d1-4, dexametasona (Xianju Pharmaceutical Co. Ltd) $20 \mathrm{mg}$ d1-4 y 15-18, y talidomida $50 \mathrm{mg}$ qn y fue dado de alta del hospital tres semanas después. (18)

Caso \# 8 Rosa María Vicuña-González, 2013, exhibe cuatro casos de plasmocitomas que afectaron la duramadre y los huesos del cráneo suprayacentes; se trató de tres hombres y una mujer con edades comprendidas entre 55 y 73 años, todos ellos con lesiones muy grandes que se resecaron con diagnóstico clínico y por imagen de meningioma con grandes lesiones, recibe diagnóstico histopatológico de plasmocitomas se efectuaron estudios de extensión y en todos los pacientes se encontró mieloma múltiple. El Paciente 1: fue tratado con dexametasona, talidomida y alopurinol. Se desconoce los resultados ya que no acudió más a las consultas. Paciente 2: microalbuminuria de $80 \mathrm{mg} / \mathrm{dL}$ y aspirado de médula ósea con $25 \%$ de células 
plasmáticas, por lo que se diagnosticó mieloma múltiple y se dieron cinco ciclos de quimioterapia en el 2005, se encuentra en buenas condiciones. Paciente 3: tratamiento de mantenimiento a base de dexametasona y talidomida, se encuentra estable. Paciente 4: tratamiento con dexametasona y talidomida. El paciente se deterioró y a un año de la cirugía se encuentra vivo pero con gran discapacidad física. (19).

Caso \# 9 Núñez MJM, 2010, reporta el caso de un paciente masculino de 77 años de edad, quien acudió a consulta estomatológica para reemplazo de prótesis dental total, manifestando durante el interrogatorio dolor y parestesia asociada a la detección de un aumento de volumen en región retromolar mandibular y carrillo derecho dolor y parestesia asociada a la detección de un aumento de volumen en región retromolar mandibular y carrillo derecho, radiográficamente se identificaron lesiones en forma de sacabocados. Se confirmó el diagnóstico de Mieloma múltiple por presencia de plasmocitoma mandibular con ratificación histológica y no especifica el tratamiento ni evolución. (20)

Caso \# 10 Andrés Ruiz, paciente femenino de 64 años de edad, natural del Estado Miranda, quien refiere inicio de su enfermedad aproximada- mente en mayo de 1984, con dolor a la palpación de la columna vertebral y tumor en la región occipital de un centímetro de diámetro, con aumento progresivo hasta alcanzar gran tamaño. Los diagnósticos clínicos fueron identificados el Síndrome anémico, Mieloma múltiple o carcinoma oculto y quiste subperióstico occipital. En su evolución desarrolla neumonía intrahospitalaria, la cual es tratada con cefalotina, amikacína y carbenicilina. Se resuelve satisfactoriamente. (21).

La búsqueda documental respecto a los métodos diagnósticos de mieloma múltiple destaca las enunciadas en la tabla \# 1.

Tabla \# 1. Pruebas o métodos para realizar el Diagnostico de MM

\begin{tabular}{|l|l|l|}
\hline $\begin{array}{c}\text { Convencional- } \\
\begin{array}{c}\text { Primer nivel } \\
\text { atención }\end{array}\end{array}$ & \multicolumn{1}{|c|}{ Especificas } & OtroS \\
\hline Historia clínica completa & Nefelometría de IgG, IgA e IgM & Imagen por resonancia magnética \\
\hline Biometría hemática completa & $\begin{array}{l}\text { Cadenas ligeras libres en suero (FLC, del inglés free light } \\
\text { chain) y su relación K/L (kappa/lambda) }\end{array}$ & Escaneo por tomografía computada, sin medio de contraste \\
\hline
\end{tabular}




\begin{tabular}{|c|c|c|}
\hline $\begin{array}{l}\text { Velocidad de sedimentación } \\
\text { eritrocitaria }\end{array}$ & Cuantificación de inmunoglobulinas séricas & Escaneo por tomografía con emisión de positrones, \\
\hline $\begin{array}{l}\text { Pruebas de función renal, } \\
\text { BUN/creatinina }\end{array}$ & $\begin{array}{l}\text { Electroforesis de proteínas séricas -Electroforesis de } \\
\text { proteínas totales en orina de } 24 \text { horas }\end{array}$ & $\begin{array}{l}\text { Biopsia de tejido para diagnosticar plasmocitoma solitario } \\
\text { óseo o extraóseo }\end{array}$ \\
\hline $\begin{array}{l}\text { Deshidrogenasa láctica en suero } \\
(\mathrm{DHL})\end{array}$ & $\begin{array}{l}\text { Inmunofijación en suero y orina (identificación de las } \\
\text { cadenas ligeras y pesadas de inmunoglobulinas) }\end{array}$ & Densitometría ósea \\
\hline Albúmina - Calcio sérico & $\begin{array}{l}\text { Evaluación de médula ósea mediante aspirado y biopsia } \\
\text { unilateral, que incluye inmunohistoquímica, citometría } \\
\text { de flujo o ambas (biopsia por trefina de al menos } 20 \\
\mathrm{~mm} \text { de longitud) }\end{array}$ & Índice de marcaje de células plasmáticas, \\
\hline & $\begin{array}{l}\text { Citogenética mediante hibridación in situ por } \\
\text { fluorescencia (FISH) específicamente para determinar } \\
\text { las mutaciones siguientes: del13, del17p13, t(4;14), } \\
\mathrm{t}(11 ; 14), \mathrm{t}(14 ; 16) \text {, amplificación 1q21 }\end{array}$ & $\begin{array}{l}\text { Tinción de médula y cojín graso para identificación de } \\
\text { amiloide }\end{array}$ \\
\hline & $\begin{array}{l}\text { Investigación ósea: radiografías simples de columna } \\
\text { vertebral cervical, torácica y lumbar, pelvis, cráneo } \\
\text { (anteroposterior y lateral), huesos humerales y } \\
\text { femorales, radiografía posteroanterior y } \\
\text { anteroposterior de tórax, serie ósea. }\end{array}$ & Viscosidad sérica y Tipificación de HLA \\
\hline
\end{tabular}

Revista de hematología, Martha Alvarado-Ibarra, 2015

$(22)$

Cabe recalcar que actualmente se está realizando un gran esfuerzo científico para redefinir el monitoreo de la respuesta del tratamiento del mieloma múltiple (MM), lo que resulta en el desarrollo y la validación de técnicas de alta sensibilidad para detectar la enfermedad residual mínima (MRD). En 2016, el Grupo Internacional de Trabajo sobre el Mieloma (IMWG) actualizó las categorías de respuesta MM que definen las respuestas negativas a MRD tanto en la médula ósea (evaluada por cartometría de flujo de próxima generación o secuenciación de próxima generación) como fuera de la médula ósea. Sin embargo, muchas preguntas sobre el uso clínico del estado de MRD siguen sin respuesta. (23).

\section{DISCUSIÓN}

En un estudio denominado enfermedad residual medible por citometría de flujo de próxima generación en mieloma múltiple elaborado por Bruno Paive y publicado en la revista J Clin Oncol en el 2020, determinó la aplicabilidad y la sensibilidad del flujo MRD-negativo criterio definido por el International Myeloma Working Group para evaluar el MM en 458 pacientes, y resulto que el criterio de respuesta negativa a MRD de flujo IMWG es altamente aplicable y sensible para evaluar la eficacia del tratamiento en MM. (24) 
Por otro lado, Oliva y colb, 2020 realiza una mini revisión que se centra en las técnicas y datos disponibles actuales sobre las pruebas de enfermedad residual mínima (MRD) y sus posibles aplicaciones futuras, concluye que el monitoreo de MRD puede guiar la intensidad del tratamiento, aunque se necesitan ensayos clínicos bien diseñados para demostrar este potencial. (23)

En relación a F-FDG PET / CT ya ha demostrado mejor desempeño que la Gammagrafía de cuerpo entero (99m) Tc-MIBI en la detección de lesiones focales, mientras que $(99 \mathrm{~m})$ Tc-MIBI es superior en la visualización de la enfermedad difusa, según J Nucl Med en el 2008, por Rosa Fonti, et al, resalta sus resultados positivos sobre 32 pacientes vs la $(99 \mathrm{~m})$ Tc-MIBI fue positiva en 30 pacientes. (25).

Sin embargo Miroslav Myslivecek 2008, señala que $(99 \mathrm{~m})$ la gammagrafía con Tc-MIBI y la MRI son métodos de igual sensibilidad para detectar MM activa y complementarse entre sí. La ventaja de la gammagrafía con $99 \mathrm{mT}$ c-MIBI es la posibilidad de un examen de todo el cuerpo, que permite la superioridad en la detección de $\mathrm{MM}$ en el esqueleto apendicular y las lesiones extramedulares, y una respuesta más rápida a la terapia, mientras que la ventaja de la RM es la detección de masas epidurales y las compresiones vertebrales que influyen La estrategia terapéutica. (26).

Además, para el diagnóstico del mieloma múltiple en atención primaria, la una historia clínica apropiada es una herramienta fundamental desde el inicio, además debe incluir, al menos, un conteo sanguíneo completo, bioquímica, proteína total, electroforesis de proteínas, inmunofijación y radiografías de áreas dolorosas (27).

\section{CONCLUSIONES}

La historia clínica biometría hemática, bioquímica, proteína total, electroforesis de proteínas, inmunofijación y radiografías de áreas dolorosas son pruebas de laboratorio usadas en la atención primaria de salud en el contexto del paciente con MM.

Los métodos más invasivos se encuentra la biopsia de hueso permite valorar el patrón de infiltración de la médula ósea por las células plasmáticas.

Para confirmar el diagnóstico de mieloma se debe demostrar un fenotipo o una monoclonalidad aberrante de la célula plasmática, los estudios citogenéticos mediante FISH y la beta-2-microglobulina y de albúminas séricas son de gran utilidad para establecer el pronóstico del paciente

Otros métodos como la resonancia magnética permiten para evaluar el patrón de afectación, y determinar enfermedad oculta y plasmocitomas; la tomografía computada debe realizarse en pacientes con datos sugerentes de compresión medular cuando no se disponga de resonancia magnética o esté contraindicada, y emisión de positrones (PET) no se recomienda como estudio de rutina, sino en casos selectos para aclarar dudas. No obstante, quedan dudas aún sin responder sobre estos métodos que la evolución clínica del paciente.

\section{REFERENCIAS}


1. Alvarado-Ibarra M ea. Primer Consenso Nacional de Mieloma Múltiple por Hematólogos del ISSSTE. Rev Hematol Mex. 2015; 4: p. 306-332.

2. Subirós RM VGERBG. Mielitis transversa post picadura de abeja, primer reporte de caso en Costa Rica. Rev Med Cos Cen. 2016;: p. 717-724.

3. Natalia García Allende MJGPMFRAVSMMWVR. Mielitis transversa aguda en un viajero. MEDICINA (Buenos Aires). 2016;: p. 242-244.

4. Presas-Rodríguez S GLLHGJMVARTC. Mielitis : diferencias entre la esclerosis múltiple y otras etiologías. Neurologia. 2016 Marzo;: p. 71-5.

5. Dra. Victoria Estabén Boldova DCLMDBSY. Mielitis transversa aguda. Revista Atalaya Medica. 2015;: p. 52-56.

6. Javier Saldaña LLCNS. Mielitis transversa aguda postviral, reporte de caso en la ciudad de Cali. Salutem Scientia Spiritus. 2016 Dec 30; 2.

7. Alejandro Moya Valdés LAGLYOÁAJGMMCH. Mielitis transversa aguda asociada al puerperio. Universidad Médica Pinareña. 2017.

8. Raúl Menor Almagroa MdMRTJGÚMHCRJJPVCGG. Mielitis transversa en síndrome de Sjögren y lupus eritematoso sistémico: presentación de 3 casos. Reumatología Clínica. 2015;: p. 41-44.

9. Joven $\vee 1$ QG. Trastornos del espectro óptico de mielitis transversa y neuromielitis. Semin Ultrasonido CT MR. 2016 Octubre; 5: p. 384-95.

10. Hu H TX,YJ. Mielitis transversa corta en pacientes chinos con neuromielitis con trastornos del espectro óptico. Mult Scler Relat Disord. 2018 Abril;: p. 78-83.

11. Edson Hernán CJPHEC. Mielitis y lupus: clínica, diagnóstico y tratamiento. Revisión. Reumatología Clínica. 2017 Noviembre - Diciembre;: p. 344-348.

12. Cecilia Martínez MDHSLdVPCMAMMDHLIRVQCMCE. Mielitis Transversa Análisis Clínico. Rev. Méd. Risaralda. 2018; 24(2): p. 139-142.

13. Castro Jordan VF, Castillo Solís J. Miolema Múltiple. Revista Científica Ciencia Médica. 2008; 11(1): p. 21-24.

14. Maribel Quintero ARAARMGJHFAWDKUyFP. Anomalías cromosómicas en pacientes. Invest Clin. 2003; 44(4): p. 327-335.

15. Dr. Hermes Moreno Ramírez DJCVMDABVM. Progresión de plasmocitoma óseo a mieloma múltiple y reporte de un caso. Rev Cubana de Investigaciones Biomédicas. 2015; 44(3).

16. Dr. Luis G. Ramón Rodríguez DOALDCHPDEEMDRLBDOÁCDAGDDMGMDAHC. Mieloma múltiple y embarazo. Primer reporte de caso en Cuba. Revista Cubana de Hematología, Inmunología y Hemoterapia. 2010; 26(1).

17. Irene Castro CASVYCC. Mieloma múltiple en pacientes con lupus eritematoso sistémico: presentación de dos casos. Revista médica de Chile. 2018; 146(5).

18. Zhou HB. Un caso de mieloma múltiple que se presenta inicialmente como hematemesis. Turk J Gastroenterol. 2018 Enero; 29(1): p. 108-111. 
19. Rosa María Vicuña-González MIRSPMPGVPGP. Plasmocitoma dural como primera manifestación de mieloma múltiple. Informe de cuatro casos y revisión bibliográfica. Patología Revista Latinoamericana. 2013; 51: p. 3-12.

20. Núñez MJM CUPBAM. Mieloma múltiple IgA con manifestación craneofacial Reporte de caso clínico y revisión de la literatura. Rev ADM. 2010; 67(1).

21. Dr. Andrés Ruiz DATDRO. Plasmocitoma Extramedular pobremente diferenciado. Primera manifestación de un mielema múltiple. Dermatología Venezolana. ;: p. 9-11.

22. Revista de Hematologia. Primer Consenso Nacional de. Revista de Hematologia Mexicana. 2015; 16: p. 306-332.

23. Oliva -Estefania ea. Aplicaciones clínicas y direcciones futuras de las pruebas de enfermedad residual mínima en el mieloma múltiple. Unidad de mieloma, División de Hematología, Universidad de Torino, Azienda Ospedaliero-Universitaria Cittá Della Salute e Della Scienza di Torino, Turín, Italia. 2020 Enero 31;: p. doi.org/10.3389/fonc.2020.00001.

24. Paive-Bruno ea. Enfermedad medible por citometria de flujo. J Clin Oncol. 2020; 38(8): p. 784-792.

25. Fonti-Rosa ea. 18F-FDG PET / CT, 99mTc-MIBI y MRI en la evaluación de pacientes con mieloma múltiple. J nuLd Med. 2008; 49 (2): p. 195-200.

26. Myslivecek M. Mieloma múltiple: valor predictivo de la gammagrafía y la resonancia magnética de Tc-99m MIBI en su diagnóstico y terapia. Nucl Med Rev Cent East Eur. 2008; 11(1): p. 12, 16.

27. MM Alvarez-Cordovés PMMAPM. Diagnostico en atencion primaria. Semergen. 2013; 39 (6): p. DOI: 10.1016 / j.semerg.2012.05.006.

28. Vázquez-Osorio IGRSRRM. Criptococosis cutánea primaria en paciente inmunocompetente. Dermatology Online Journal. 2016; 5(22). 